\title{
Autosomal recessive limb-girdle muscular dystrophy type 2T
}

INSERM

\section{Source}

INSERM. (1999). Orphanet: an online rare disease and orphan drug data base. Autosomal recessive limb-girdle muscular dystrophy type 2T. ORPHA:363623

Autosomal recessive limb-girdle muscular dystrophy type $2 \mathrm{~T}$ (LGMD2T) is a form of limb-girdle muscular dystrophy, that can present from birth to early childhood, characterized by hypotonia, microcephaly, mild proximal muscle weakness (leading to delayed walking and difficulty climbing stairs), mild intellectual disability and epilepsy. Additional manifestations reported in some patients include cataracts, nystag mus, cardiomyopathy, and respiratory insufficiency. 